\title{
The Gender Gap in Possible Selves: Divergence of Academic Self-Views Among High School and University Students
}

\author{
Hilary M. Lips ${ }^{1}$
}

\begin{abstract}
Two studies were designed to investigate the current and possible academic self-views of university and high school students. In the first study, upper level university students were shown to diverge by gender in their current- and possible-self-views. Women reported more ability for and identification with the arts, communication, and social sciences; men reported more ability for and identification with mathematics, science, technology, and business. Gender differences were greater with respect to possible future selves than to current selves. The second study included lower and upper level university students as well as high school students. Again, a gender divergence appeared among the university students; however, it was not as marked among high school students. Analyses showed that both women and men differed significantly across educational levels in their self-ratings and that, within the masculine-stereotyped academic domains linked to powerful careers, university women endorsed fewer possibilities for themselves that high school women did. These findings suggest that, as they make the transition from high school to university, young women may be actively closing off possibilities for their futures.
\end{abstract}

KEY WORDS: possible selves; gender; mathematics and science.

Researchers long ago moved from viewing the self-concept as simply a collection of self-attributed traits to seeing it as a lens through which individuals perceive and organize reality. It is argued that individuals see situations through the lens of their own self-views and that individual differences in construal make a difference in the way situations impact on people (e.g., Ross \& Nisbett, 1991). Constructivist approaches posit something even more complex: that humans actively create and construe our personal realities-that each person creates his or her own representational model of the world and that this model does not simply act as a filter through which ongoing experience is perceived, but that the model actually creates and constrains new experience, and so shapes what the person will perceive as "reality" (e.g., Mahoney \& Lyddon, 1988). Indeed, research suggests

\footnotetext{
${ }^{1}$ To whom correspondence should be addressed at Department of Psychology, Box 6946, Radford University, Radford, Virginia 24142; e-mail: hlips@radford.edu.
}

a central role for the self in motivation and behavior (Brown, 1998). Thus, self-views are important for understanding many behavioral choices, including the persistent tendency for male and female students to separate into different academic and career paths and the resistance of many young women to science and technology careers.

A wealth of psychological literature illustrates that the self-concept in various guises, and in interaction with the social context, shapes the academic and occupational choices that people make with respect to mathematics and science. For example, having a positive or negative self-schema with respect to mathematics and science, as opposed to having no self-schema or only a weak self-schema for this domain, has been systematically linked to a variety of tangible outcomes: performance on in-lab math tests, past math/science course enrollment, confidence with respect to career possibilities in math and science, intent to take more math/science courses, and the number of math/science courses actually taken 
for 3 years subsequent to the self-schema assessment (Lips, 1995). Gender and self-evaluation moderate the effects of perceived supportiveness of academic departments: female graduate students whose selfevaluation of their abilities is low have been shown to be most vulnerable to nonsupportive academic environments (Cross, 2001). Female engineering students with interdependent self-construals are more influenced than those with independent self-construals by social support in their academic environments (Cross \& Vick, 2001). Female college students, even those who select math-intensive majors, have difficulty associating math with the self if they implicitly stereotype mathematics as masculine (Nosek, Banaji, \& Greenwald, 2002).

Not only current self-views, but also possible selves (Markus \& Nurius, 1986) are likely to be important in decisions regarding academic and career paths. A view of the current self as positively inclined to math and science may be differentially related to selfperceived career possibilities for women and men. Despite their current-self perceptions as positively inclined toward mathematics and science, women in one study could not, or would not, construct possible selves in the realm of engineering and the physical sciences-perhaps because such possible selves were at odds with their notions about femininity, or perhaps because they had no female role models in these areas to help them articulate a possible self (Lips, 1993). The latter study, carried out with 97 university students, indicated that endorsing a self-description as inclined toward mathematics and science was positively related to endorsing career likelihood in the physical sciences and engineering for male, but not female, respondents.

Gender has traditionally been one of the bases on which possibilities are embraced, ignored, or relinquished. On the basis of their gender, students may be encouraged or discouraged from certain choices and may learn to view themselves as fitting well or poorly into certain roles (e.g., Eagly, 1987; Eccles, 1987; Räty, Vänskä, Kasanen, \& Kärkkäinen, 2002). For example, female university students in male-dominated academic areas report higher levels of discrimination and stereotype threat than do women in femaledominated academic areas (Steele, James, \& Barnett, 2002).

The construction of current- and possible-selfviews is a dynamic process (Brown, 1998; Markus \& Nurius, 1986). Thus, students are actively constructing their futures as they construct their self-views and, reciprocally, are actively adjusting their self-views to fit the futures they are envisioning. In this process, women and men may be diverging more and more in their sense of possibility.

Some research on the academic choices made by young women and men suggests such an increasing divergence over time. For example, Ivie and Stowe's examination of U.S. women in academic physics showed that, although almost half of high school physics students are women, women are poorly represented at the bachelor's level and higher and that women's participation in physics decreases with each step up the academic ladder (Ivie \& Stowe, 2002). Gaudet and Lapointe's (2002) study of French Canadian girls showed that, in high school, these girls choose courses that give them the prerequisites for science and technology programs, but that they steer away from such programs when they enroll in college or university. Female high school students who show high ability and interest in science in their senior high school years often choose nonscientific career pathways as they progress through postsecondary education (AdamutiTrache \& Andres, 2002). Research on students in a university engineering program designed specifically to be woman-friendly showed that women's academic performance was higher than men's for the freshman and sophomore years, but that men seemed to catch up in the last 2 years. Furthermore, female students experienced a noticeable drop in confidence in their engineering abilities in senior year, at a time when male students displayed a surge in self-confidence (Hartman \& Hartman, 2002). If there is an increasing divergence, it may be partly because, as they approach academic and career decision points, young women envision future difficulties, even if they view themselves as currently competent in science, engineering, and technology. Steele et al. (2002) found that female students in a male-dominated area anticipated more future sex discrimination and thought more about changing their major than did their counterparts in traditional fields.

The research reported here represents an attempt to explore the links between various components of the current and possible academic selfconcept and the ways that these components may diverge for young women and men as they move through their education. It was hypothesized that women and men would differ in their current and possible academic self-views, with each group endorsing more gender-stereotypic items. It was further predicted that the gender difference would be more pronounced in the realm of possible- than currentself concepts. Finally, it was hypothesized that the 
gender divergence in possible academic selves would be greater for students at more advanced educational levels.

\section{STUDY 1}

\section{Method}

\section{Participants}

The LASS was administered to sample of undergraduate students at a medium-sized comprehensive public university in the southeastern United States (RU-A, $n=738$ ). Twenty respondents were dropped because of missing data. Every attempt was made to obtain a heterogeneous sample with a good representation of male and female respondents with varied interests. Thus, the survey was administered in many types of classes, such as dance, computer science, and criminal justice. In addition, the survey was administered twice, 3 weeks apart, to a subsample of 72 respondents as a check on test-retest reliability.
The RU-A sample was $60 \%$ female and had a mean age of 21.6 years. Sixty-eight percent of the respondents listed their race as European American, 5\% as African American, 2.6\% as Hispanic American, $2.4 \%$ as Asian American, $1.9 \%$ as American Indian. The remaining respondents did not specify race/ethnicity or listed themselves as "other." Class composition of the sample was: $4.1 \%$ freshmen, $16.8 \%$ sophomores, $44.5 \%$ juniors, and $34.6 \%$ seniors. They represented 40 different academic majors; the most common were physical education, nursing, accounting, information systems, management, marketing, psychology, and social work.

\section{Materials}

The Lips Academic Self-View Survey (LASS; Lips, 1996, 1998) was used to investigate students' current and possible academic self-views. The currentacademic-self section of the LASS (see Table I) contains 30 items relevant to ability in and enjoyment of a number of different activities relevant to academic performance (e.g., poor with numbers; good in artistic,

Table I. Formation of Composite Scores From Individual LASS Current-Self Items

\begin{tabular}{|c|c|c|}
\hline Item & Composite & Higher order composite \\
\hline $\begin{array}{l}\text { Enjoy learning math } \\
\text { Good with numbers } \\
\text { Good in math } \\
\text { Poor with numbers }(-) \\
\text { Poor in math }(-) \\
\text { Dislike learning math }(-)\end{array}$ & $\begin{array}{l}\text { Enjoy/good with } \\
\text { math and numbers }\end{array}$ & Math/Science (MSci) \\
\hline $\begin{array}{l}\text { Enjoy using math in science } \\
\text { Good in science } \\
\text { Enjoy learning science } \\
\text { Poor in science }(-) \\
\text { Dislike learning science }(-)\end{array}$ & $\begin{array}{l}\text { Enjoy/good in } \\
\text { science }\end{array}$ & \\
\hline $\begin{array}{l}\text { Good at debating and arguing } \\
\text { Good at abstract reasoning }\end{array}$ & $\begin{array}{l}\text { Good at reasoning, } \\
\text { arguing viewpoints }\end{array}$ & \\
\hline $\begin{array}{l}\text { Limited ability in using computers } \\
\text { Limited ability in math/science }\end{array}$ & $\begin{array}{l}\text { Limited ability in } \\
\text { math and computing }\end{array}$ & \\
\hline $\begin{array}{l}\text { Limited artistic ability } \\
\text { Limited ability in writing }\end{array}$ & $\begin{array}{l}\text { Limited ability artistically } \\
\text { and in writing }\end{array}$ & Arts/literature/comm (ACL) \\
\hline $\begin{array}{l}\text { Good at writing papers } \\
\text { Enjoy writing papers } \\
\text { Poor at writing papers }(-) \\
\text { Dislike writing papers }(-)\end{array}$ & $\begin{array}{l}\text { Enjoy/good at } \\
\text { writing }\end{array}$ & \\
\hline $\begin{array}{l}\text { Good in artistic/creative work } \\
\text { Enjoy learning fine arts } \\
\text { Dislike learning fine arts }(-) \\
\text { Poor in artistic/creative work }(-)\end{array}$ & $\begin{array}{l}\text { Enjoy/good at artistic/ } \\
\text { creative work }\end{array}$ & \\
\hline $\begin{array}{l}\text { Enjoy helping others } \\
\text { Good at working with people }\end{array}$ & $\begin{array}{l}\text { Enjoy/good at working with/ } \\
\text { helping others }\end{array}$ & \\
\hline
\end{tabular}


Table II. Formation of Composite Scores From Individual LASS Possible-Self Items

\begin{tabular}{|c|c|c|}
\hline Item & Composite & Higher order composite \\
\hline \multicolumn{3}{|l|}{ Pursuing studies in } \\
\hline $\begin{array}{l}\text { Physical sciences (e.g., physics, } \\
\text { astronomy, chemistry) }\end{array}$ & Natural sciences & Power $^{a}$ \\
\hline \multicolumn{3}{|l|}{$\begin{array}{l}\text { Planetary science (e.g., ecology, } \\
\text { geology, geography, oceonography, weather) }\end{array}$} \\
\hline $\begin{array}{l}\text { Business (e.g., accounting, management, } \\
\text { marketing, information systems) }\end{array}$ & Business/math & \\
\hline \multicolumn{3}{|l|}{$\begin{array}{l}\text { Mathematics (e.g., pure, applied, biometric, } \\
\text { econometric, statistical) }\end{array}$} \\
\hline \multicolumn{3}{|l|}{$\begin{array}{l}\text { Computer Science (e.g., AI, networking, } \\
\text { programming) }\end{array}$} \\
\hline $\begin{array}{l}\text { Humanities (e.g., art, literature, history } \\
\text { languages, philosophy, religion) }\end{array}$ & Humanities/culture & People \\
\hline \multicolumn{3}{|l|}{$\begin{array}{l}\text { Fine Arts (e.g., art, dance, graphic arts, } \\
\text { design, music, theater) }\end{array}$} \\
\hline \multicolumn{3}{|l|}{$\begin{array}{l}\text { Ethnicity \& race (e.g., African American, } \\
\text { Appalachian, Asian, Hispanic Studies) }\end{array}$} \\
\hline $\begin{array}{l}\text { Social Sciences (e.g., anthropology, } \\
\text { communication, political science, } \\
\text { psychology, sociology) }\end{array}$ & Social/behavioral science & \\
\hline $\begin{array}{l}\text { Teaching (e.g., education, athletics, } \\
\text { administration) }\end{array}$ & & \\
\hline
\end{tabular}

${ }^{a}$ This higher order composite also included possible-self items for engineering, law, and renewable resources.

creative work; enjoy learning science). There is a fivechoice-graded set of response choices for each item that ranges from not me to definitely me. For each item, respondents were instructed to "select and clearly circle one of the terms that most clearly represents the extent to which the numbered item is or is not you." The possible-academic-self section (see Table II) consisted of 15 items that refer to pursuing further studies in particular academic areas (e.g., physical science, business, fine arts). This section follows a similar fivechoice format, with responses that range from not a possible me to definitely a possible me. For each item, respondents were instructed to circle the term "that most closely represents the extent to which pursuing further studies in the area is or is not a possible you." The response choices have been shown to represent a progressive linear increase in willingness to see the current or possible self in a certain manner, and responses at the extremes of the scale represent a greater certainty and a narrower, cleaner range of meaning than the middle responses (Lips \& Casey, 1996). The survey was developed and tested on samples from two colleges: a small 2-year public college and a medium-sized comprehensive public university in the southeastern United States (Lips, 1996; Lips \& Wilson, 1997). A system of composite scores was developed on the basis of subsequent administrations of the LASS to samples at four colleges: a small private college and a medium-sized public university in the southeastern United States and a medium-sized and a large university in western Canada (Lips, 1998).

In earlier studies, interitem correlations for items thought to measure the same current-self dimensions ranged from .47 to .82 , and average test-retest reliability for individual items was .689 (Lips, 1998). Four forms of the LASS, which differed in section order and in item order within sections, were used to control for order effects.

\section{Procedure}

Permission was obtained from instructors to administer the LASS during class time. The purpose of the study was explained to students at the beginning of the session, and they were asked to complete the survey voluntarily. Anyone who did not wish to respond was told to hand back a blank questionnaire. In most classrooms there was very high compliance; no more than two or three students in any class declined to participate. The time required was approximately $20 \mathrm{~min}$.

\section{Analysis}

Composite Scores. Following the method used in Lips (1998), in order to examine the themes and patterns in the data, composite scores were constructed 
by averaging the scores for academically meaningful sets of items-items that "go together" in the sense that they tend to be related to the structure of choices presented to students in actual academic programs and majors. Current-self items were grouped into eight composite scores according to patterns that fit together in broad academic topic areas or related abilities, such as math and science, the arts, or literature and writing. Table I shows the grouping of individual items into the current-self composite scores used in the analysis. Possible-self items were also grouped into constellations of responses that represented themes, such as natural sciences or life/health sciences. Table II shows the grouping of individual items into the possible-self composite scores used in the analysis.

Higher Order Composite Scores. Beyond the immediate academic themes, are broader, higher order themes that may represent bias toward or away from entire possible-self domains. Two higher order current-self composites that reflected the broad themes of academic self-views that have often differentiated women and men were created: the Math-Science Composite (MSci: a combination of all math and science items) and the Art/Literary/Communication Composite (ACL: a combination of all items concerning writing, art, and working with people). Two higher order possibleself composites that reflected similar broad themes were created: the Power Composite (the sum of all math-, science-, computing-, business, and law-related items) and the People Composite (the sum of all items related to humanities, fine arts, education, and social-behavioral studies). The Power composite is so named because the academic areas that comprise it frequently form the educational backgrounds of political and business leaders in the United States (e.g., Ornstein, Mann, Malbin, \& Bibby, 1993; The Corporate Elite, 1993). Tables I and II show the relationship of these higher order composites to the lower-order composites.

Factor Analysis. For each data set, the currentself and possible-self items were subjected to factor analysis to confirm the plausibility of the higher order composites.

\section{Results}

\section{Reliability}

Using data from the test-retest subsample, Cronbach's alpha was calculated item by item, using the test and retest score on each item. The average alpha for the current-self items was .659, with a standard deviation of .116. The average alpha for the possible-self items was .718, with a standard deviation of .063. For the current-self composite scores, alphas ranged from .797 to .962 ; for the possible-self composites, alphas ranged from .757 to .905 .

\section{Gender Differences on Composite Scores}

Current-Self Composites. Two current-and-possible-self domains were conceptualized, such that one domain represented the realm of mathematics, science, and business, and the other represented the arts, culture, and communication. To examine the relationship between gender and domain for the current-self composites, a mixed $2 \times 2 \times 4$ (gender $\times$ domain $\times$ individual composite) multivariate analysis of variance (MANOVA), with the eight current-self composites used as repeated measures, was performed. The analysis revealed a significant interaction of gender $\times$ domain, $F(1,716)=42.54$, $p<.0001$. The interaction describes a pattern in which men's self-ratings were higher than women's on the linear combination of masculine-stereotyped composites Math, Science, Arguing, and (reversed) Limited Ability in Math/Computing, and women's self-ratings were higher than men's on the combination of feminine-stereotyped composites Writing, Art, Helping, and (reversed) Limited Artistic/Writing Ability. A MANOVA using the eight composites as dependent variables revealed a significant multivariate effect of gender, $F(8,709)=16.98$, $p<.0001$. Subsequent univariate analyses showed that women and men differed significantly on all but two of the composites: Limited Ability in Writing/Artistic Ability, and Enjoy/Good at Writing. Means and standard deviations for the current- and possible-self primary composite scores are shown in Table III.

Possible-Self Composites. To examine the relationship between gender and domain for the possibleself composites, a mixed $2 \times 2 \times 2$ (gender $\times$ domain $\times$ composite) MANOVA was performed. The analysis showed that the interaction between gender and domain was significant, $F(1,716)=52.47$, $p<.0001$; women scored higher on the Humanities/Culture and Social/Behavioral Science composites, and men scored higher on the Natural Sciences and Business/Math composites. A MANOVA using the four composites as dependent variables revealed a significant multivariate effect of gender, 
Table III. Current- and Possible-Self Composite Scores by Gender for University Students (Study 1)

\begin{tabular}{|c|c|c|c|c|}
\hline \multirow[b]{2}{*}{ Variables } & \multicolumn{2}{|c|}{ Women } & \multicolumn{2}{|c|}{ Men } \\
\hline & Mean & $S D$ & Mean & $S D$ \\
\hline \multicolumn{5}{|l|}{ Current-self composites } \\
\hline Limited ability: math/computing** & 3.51 & 0.971 & 3.77 & 0.876 \\
\hline Limited artistic ability & 3.77 & 0.885 & 3.67 & 0.900 \\
\hline Enjoy/good at math, numbers** & 2.88 & 1.302 & 3.14 & 1.214 \\
\hline Enjoy, good in science* & 2.92 & 1.101 & 3.09 & 1.038 \\
\hline Enjoy, good at writing & 3.47 & 1.160 & 3.31 & 1.170 \\
\hline Enjoy, good at artistic work ${ }^{* *}$ & 3.59 & 1.024 & 3.27 & 1.092 \\
\hline Good at debating, arguing ${ }^{* *}$ & 3.41 & 0.912 & 3.74 & 0.886 \\
\hline Enjoy, good at working with others** & 4.65 & 0.581 & 4.24 & 0.792 \\
\hline \multicolumn{5}{|l|}{ Possible-self composites } \\
\hline Natural sciences ${ }^{* *}$ & 1.78 & 0.947 & 2.06 & 0.994 \\
\hline Business/math** & 2.24 & 1.000 & 2.77 & 0.981 \\
\hline Social/behavioral sciences ${ }^{* *}$ & 3.17 & 1.113 & 2.82 & 1.101 \\
\hline Humanities/culture & 2.37 & 0.981 & 2.25 & 0.927 \\
\hline
\end{tabular}

$F(4,713)=16.89, p<.0001$. Subsequent univariate analyses showed that women and men differed significantly on all but one of the composites: Humanities/ Culture.

\section{Higher Order Composites}

A $2 \times 2 \times 2$ (gender $\times$ domain $\times$ current- vs.possible-self) mixed MANOVA revealed a significant three-way interaction, $F(1,716)=10.37, p<.001$.
Women tended to rate themselves higher than men did within the domain that included the arts and communication emphasis, whereas men tended to rate themselves higher within the domain that included the mathematics and science emphasis. Within each domain, women and men were further apart on the possible-self composites than on the current-self composites; however, this tendency was strongest within the masculine-stereotyped domain that includes math and science. Figure 1 illustrates the results of this

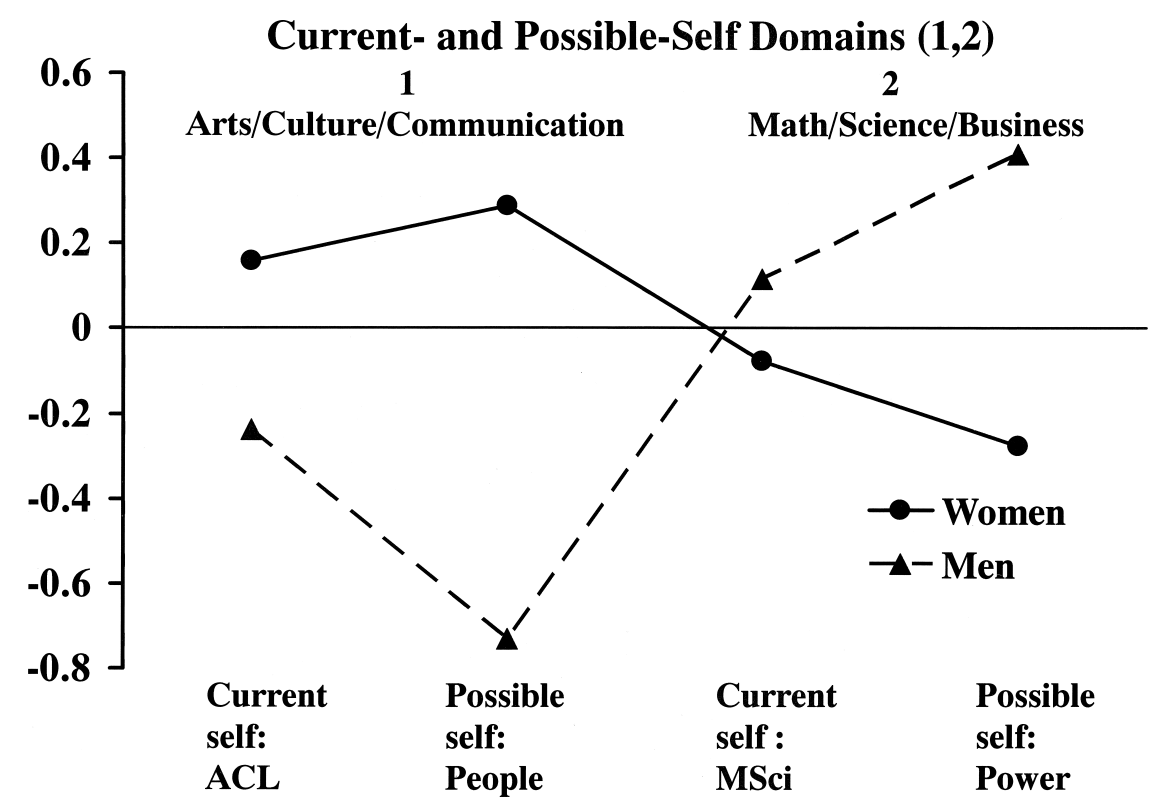

Fig. 1. Means for the higher order current- and possible-self composites (as $z$ scores) in the RU-A data set. 
analysis. A MANOVA using the four higher order composites as dependent variables revealed a significant effect of gender, $F(4,713)=31.37, p<.0001$. Subsequent univariate analyses showed that women and men differed significantly on all four composites.

\section{Factor Analysis}

As a check on the plausibility of the composite variables, principal components analyses on the current-self items, using varimax rotation and restricted to two factors, produced a pattern similar to the higher order composite scores identified above. One of the factors shows high loadings for math- and science-related items, whereas the other shows high loadings for items concerned with writing and artistic ability. Table IV shows the loadings of individual items on the two current-self components.

A similar analysis was performed for the possible-self items. Table $\mathrm{V}$ shows the loadings of in- dividual items on the two possible-self factors. As expected, one factor shows high loadings for items relevant to the physical and natural sciences and the other shows high loadings for items relevant to the humanities and social sciences.

\section{DISCUSSION}

The findings indicate the presence of a significant gender divide among university students in terms of academic self-views, particularly in the realm of possible selves. The findings parallel those obtained in samples of students from other U.S. colleges (Lips \& Wilson, 1997) and two Canadian universities (Lips, 1998). However, because most of the students in this sample were juniors and seniors, the data provide no window on the possible time course for the emergence of this gender divide. Thus, in the next wave of data collection, students were recruited from first-year university classes and from high schools.

Table IV. Loadings of Individual Current-Self Items on Rotated Components ${ }^{a}$

\begin{tabular}{|c|c|c|}
\hline \multirow[b]{2}{*}{ Item } & \multicolumn{2}{|c|}{ Item loadings } \\
\hline & Component 1 & Component 2 \\
\hline C28-Poor with people & -.801 & \\
\hline C5-Poor at abstract reasoning & -.742 & \\
\hline C23-Good with people & .717 & \\
\hline $\mathrm{C} 1-$ Good at artistic, creative work & .697 & \\
\hline C17-Limited ability in writing & -.666 & \\
\hline C29-Good in math & -.617 & .375 \\
\hline C25-Poor at artistic, creative work & -.599 & \\
\hline C11-Enjoy helping others & .568 & \\
\hline C3-Poor at writing & -.550 & \\
\hline C7-Good at arguing views & .504 & -.409 \\
\hline C30-Enjoy writing papers & .496 & .351 \\
\hline C18-Good at abstract reasoning & .486 & .329 \\
\hline C9-Limited ability using computers & .427 & \\
\hline C15-Dislike learning math & .412 & -.402 \\
\hline \multicolumn{3}{|l|}{ C6-Dislike learning fine arts } \\
\hline \multicolumn{3}{|l|}{ C20-Enjoy learning science } \\
\hline \multicolumn{3}{|l|}{ C22-Dislike competing against others } \\
\hline $\mathrm{C} 10$-Poor in math & & -.823 \\
\hline C4-Good with numbers & & .820 \\
\hline C13-Limited artistic ability & & .523 \\
\hline C21-Enjoy learning fine arts & .300 & -.565 \\
\hline C19-Good in science & & .542 \\
\hline C26-Limited ability in math and science & & -.524 \\
\hline C14-Enjoy using math in science & -.332 & .473 \\
\hline $\mathrm{C} 2$-Enjoy learning math & & .440 \\
\hline $\mathrm{C} 12$-Poor in science & & -.392 \\
\hline C16-Dislike writing papers & -.376 & -.389 \\
\hline C8-Poor with numbers & & -.376 \\
\hline $\mathrm{C} 24-$ Good at writing & .323 & -.359 \\
\hline C27-Dislike learning science & & \\
\hline
\end{tabular}

${ }^{a}$ Loading lower than .30 are omitted. 
Table V. Loadings of Individual Possible-Self Items on Rotated Components ${ }^{a}$

\begin{tabular}{|c|c|c|}
\hline \multirow[b]{2}{*}{ Item } & \multicolumn{2}{|c|}{ Item Loadings } \\
\hline & $\mathrm{C} 1$ & $\mathrm{C} 2$ \\
\hline P10-Fine arts (e.g., dance, graphic design, music, theater) & .711 & \\
\hline $\begin{array}{l}\text { P13-Social sciences (e.g., anthropology, sociology, communication, psychology, media, } \\
\text { political science) }\end{array}$ & .652 & \\
\hline P12-Education (e.g., administration, athletics, coaching, counseling, teaching) & .561 & \\
\hline P15-Ethnic studies (e.g., African American, Appalachian, Asian studies) & .514 & \\
\hline P4-Humanities (e.g., art, literature, history, languages, philosophy, religion) & .511 & \\
\hline P11-Health sciences (e.g., medicine, pharmacy, physiotherapy, nursing, nutrition) & .369 & \\
\hline P8-Renewable resources (e.g., crops, forests, fisheries, livestock) & .324 & \\
\hline P14-Planetary science (e.g., ecology, geology, geography, oceanography, weather) & & \\
\hline P5-Mathematics (e.g., pure, applied, biometric, econometric, statistical) & & .657 \\
\hline P3-Engineering (e.g., architecture, civil, electrical, mechanical, systems) & & .570 \\
\hline P1-Physical sciences (e.g., physics, astronomy, chemistry) & & .545 \\
\hline P9-Computer science (e.g., AI, networking, programming) & & .539 \\
\hline P2-Business (e.g., accounting, management, marketing, information systems) & & .474 \\
\hline P6-Life sciences (e.g., biology, physiology, neuroscience, veterinary medicine) & .393 & .404 \\
\hline P7-Law and law-related areas (e.g., law, criminal justice, forensic-police science) & & .338 \\
\hline
\end{tabular}

${ }^{a}$ Loading lower than .30 are omitted.

\section{STUDY 2}

\section{Method}

\section{Participants}

The LASS was administered to a second sample of students at a medium-sized comprehensive public university in the Southeastern United States (RU-B, $n=713)$, and a high school sample $(n=447)$ was recruited from four different high schools. The university sample was $62.3 \%$ female and had a mean age of 19.8 years. The respondents listed their race as follows: $72.5 \%$ European American, $5 \%$ African American, $1.8 \%$ Hispanic American, 3.5\% Asian American, $2.2 \%$ American Indian. The remaining respondents did not specify race/ethnicity or listed themselves as "other." Class composition of the sample was $48.2 \%$ freshmen, $13.9 \%$ sophomores, $20.5 \%$ juniors, and $17.4 \%$ seniors. The most frequently listed academic majors for this group were elementary education, psychology, criminal justice, management, biology, and marketing.

The high school sample was $56.1 \%$ female and had a mean age of 16.7 years. The respondents listed their race as follows: $82.8 \%$ European American, 2.2\% African American, 2.7\% Hispanic American, $1.3 \%$ Asian American, and $1.8 \%$ as American Indian. The remaining respondents did not specify race/ethnicity or listed themselves as "other." Class composition of the sample was $2.5 \%$ in 9th grade, $4.9 \%$ in 10 th grade, $43.6 \%$ in 11 th grade, and $49 \%$ in 12 th grade.

\section{Materials}

The LASS was again used to investigate students' current and possible academic self-views. One slight modification to the survey was made, based on student feedback: in the possible-selves section of the questionnaire, psychology was separated out from the social sciences item and became an item unto itself. Thus, this section of the questionnaire went from 15 to 16 items. Two forms of the LASS, which differ only in the order in which the current-self and possible-self section are presented, were used to counterbalance for order effects.

\section{Procedure}

In high schools, permission was sought from parents for students to participate in the study. In both high schools and the university, permission was obtained from instructors to administer the LASS during class time and the procedure described in Study 1 was followed.

\section{Results}

\section{Gender Differences on Composite Scores}

Current-Self Composites. Mixed $2 \times 2 \times 4$ (gender $\times$ domain $\times$ individual composite) MANOVA were performed for the two samples separately. For the RU-B sample, there was a significant gender $\times$ domain interaction, $F(1,707)=37.63, p<.0001$. The interaction describes a pattern, similar to that of 
the RU-A sample in Study 1, in which men's selfratings were higher than women's on the linear combination of masculine-stereotyped composites Math, Science, Arguing, and (reversed) Limited Ability in Math/Computing, and women's self-ratings were higher on the combination of feminine-stereotyped composites Writing, Arts, Helping, and (reversed) Limited Artistic/Writing Ability. A MANOVA using the eight composite scores as dependent variables revealed a significant multivariate effect of gender, $F(8,700)=20.96, p<.0001$. Subsequent univariate analyses showed that women and men differed significantly, at the .01 level or lower, on all composites except Limited Ability in Writing/Artistic Ability. Means and standard deviations for the current- and possible-self primary composite scores for this sample are shown in Table VI.

For the high school sample, the mixed MANOVA also revealed a significant gender $\times$ domain interaction, $F(1,439)=23.48, p<.0001$. The pattern of means was similar to that in the RU-B sample, with the exception that the girls' mean was slightly higher than the boys' mean for the composite Limited Ability in Math/Computing (reversed). A MANOVA using the eight composite scores as dependent variables revealed a significant multivariate effect of gender, $F(8,432)=7.52, p<.0001$. Subsequent univariate analyses showed that girls and boys differed significantly only on the current-self feminine-stereotyped

Table VI. Current- and Possible-Self Composite Scores by Gender for University Sample, Study 2

\begin{tabular}{|c|c|c|c|c|}
\hline \multirow[b]{2}{*}{ Variables } & \multicolumn{2}{|c|}{ Women } & \multicolumn{2}{|c|}{ Men } \\
\hline & Mean & $S D$ & Mean & $S D$ \\
\hline \multicolumn{5}{|l|}{ Current-self composites } \\
\hline $\begin{array}{l}\text { Limited ability: math/ } \\
\text { computing** }\end{array}$ & 3.55 & 0.867 & 3.78 & 0.859 \\
\hline Limited artistic ability & 3.81 & 0.906 & 3.71 & 0.961 \\
\hline $\begin{array}{l}\text { Enjoy/good at math, } \\
\text { numbers** }\end{array}$ & 2.85 & 1.264 & 3.09 & 1.135 \\
\hline Enjoy, good in science** & 2.87 & 1.028 & 3.13 & 0.966 \\
\hline Enjoy, good at writing ${ }^{* *}$ & 3.58 & 1.094 & 3.32 & 1.057 \\
\hline $\begin{array}{l}\text { Enjoy, good at artistic } \\
\text { work }^{* *}\end{array}$ & 3.61 & 1.012 & 3.34 & 1.061 \\
\hline Good at debating, arguing** & 3.02 & 1.025 & 3.37 & 0.905 \\
\hline $\begin{array}{l}\text { Enjoy, good at working } \\
\text { with others** }\end{array}$ & 4.47 & 0.653 & 3.96 & 0.812 \\
\hline \multicolumn{5}{|l|}{ Possible-self composites } \\
\hline Natural sciences ${ }^{* *}$ & 1.78 & 0.872 & 2.12 & 1.023 \\
\hline Business/math** & 2.05 & 0.882 & 2.63 & 0.908 \\
\hline Social/behavioral sciences** & 3.14 & 1.110 & 2.62 & 1.065 \\
\hline Humanities/culture ${ }^{* *}$ & 2.30 & 0.959 & 2.06 & 0.932 \\
\hline
\end{tabular}

Table VII. Current and Possible Self Composite Scores by Gender for High School Student Sample

\begin{tabular}{|c|c|c|c|c|}
\hline \multirow[b]{2}{*}{ Variables } & \multicolumn{2}{|c|}{ Girls } & \multicolumn{2}{|c|}{ Boys } \\
\hline & Mean & $S D$ & Mean & $S D$ \\
\hline \multicolumn{5}{|l|}{ Current-self composites } \\
\hline $\begin{array}{l}\text { Limited ability: math/ } \\
\text { computing }\end{array}$ & 3.86 & 0.811 & 3.81 & 0.971 \\
\hline Limited artistic ability** & 3.85 & 0.889 & 3.61 & 1.045 \\
\hline $\begin{array}{l}\text { Enjoy, good with math/ } \\
\text { numbers }\end{array}$ & 3.06 & 1.218 & 3.28 & 1.154 \\
\hline Enjoy, good in science & 3.11 & 1.002 & 3.28 & 0.981 \\
\hline Enjoy, good at writing** & 3.24 & 1.099 & 2.88 & 1.122 \\
\hline Enjoy, good at artistic work ${ }^{* *}$ & 3.49 & 1.045 & 3.24 & 1.042 \\
\hline Good at debating, arguing & 3.11 & 0.933 & 3.11 & 1.059 \\
\hline $\begin{array}{l}\text { Enjoy, good at working } \\
\text { with others** }\end{array}$ & 4.13 & 0.894 & 3.53 & 1.135 \\
\hline \multicolumn{5}{|l|}{ Possible-self composites } \\
\hline Natural sciences & 2.13 & 1.025 & 2.207 & 1.044 \\
\hline Business/math** & 2.26 & 0.817 & 2.55 & 0.931 \\
\hline Social/behavioral sciences & 2.52 & 1.154 & 2.36 & 1.071 \\
\hline Humanities/Culture** & 2.29 & 0.943 & 2.06 & 0.905 \\
\hline
\end{tabular}

** $p<.01$.

composites: Writing, Arts, Helping, and Limited Ability in Writing/Artistic Ability. Means and standard deviations for the current- and possible-self primary composite scores for this sample are shown in Table VII.

Possible-Self Composites. For the RU-B sample, a $2 \times 2 \times 2$ (gender $\times$ domain $\times$ composite) mixed MANOVA similar analysis revealed a significant three-way interaction, $F(1,711)=60.28, p<.0001$. As in the RU-A sample, men scored higher on both the masculine-stereotyped composites (Natural Sciences and Business/Math), and women scored higher on one of the feminine-stereotyped composites (Social/Behavioral Science). However, on the other feminine-stereotyped composite, Humanities/Culture, the men's mean was slightly higher than the women's mean, and thus men and women were much further apart in the math/science/business domain than in the arts/culture/communication domain. A MANOVA using the four composites as dependent variables revealed a significant multivariate effect of gender, $F(4,708)=29.53, p<$ .0001 . Subsequent univariate analyses showed that women and men differed significantly on all of the composites.

Analysis of the high school data also revealed a significant three-way interaction, $F(1,445)=$ $25.10, p<.0001$, a pattern of means similar to that of the RU-B sample. A MANOVA using the four composites as dependent variables revealed a significant 
Table VIII. Intercorrelations Among Higher Order Composites for the Three Samples

\begin{tabular}{lccc}
\hline & RU-A $(n=718)$ & RU-B $(n=713)$ & HS $(n=447)$ \\
\hline MSci with power & $.446(p=.000)$ & $.397(p=.000)$ & $.392(p=.000)$ \\
Msci with people & $-.324(p=.000)$ & $-.216(p=.000)$ & $-.036(p>.05)$ \\
MSci with ACL & $-.183(p=.000)$ & $-.217(p=.000)$ & $.047(p>.05)$ \\
ACL with power & $-.088(p=.019)$ & $-.181(p=.000)$ & $.102(p=.031)$ \\
ACL with people & $.508(p=.000)$ & $.501(p=.000)$ & $.536(p=.000)$ \\
People with power & $.008(p>.05)$ & $.001(p>.05)$ & $.319(p=.000)$ \\
\hline
\end{tabular}

multivariate effect of gender, $F(4,442)=7.43, p<$ .0001 . Subsequent univariate analyses showed that girls and boys differed significantly on only two of the four possible-self composites: Business/Math, and Humanities/Culture. High school boys had higher average scores than high school girls on both of these composites.

\section{Higher Order Composites}

For the college sample, a $2 \times 2 \times 2$ (gender $\times$ domain $\times$ current- vs. possible-self) mixed multivariate analyses of variance revealed a significant threeway interaction, $F(1,711)=32.58, p<.0001$. The interaction describes a pattern of means in which women's self-ratings are higher than men's selfratings in the feminine-stereotyped, domain that encompasses arts, culture, and communication, whereas the gender difference is reversed in the domain that encompasses mathematics, science, and business. In the latter domain, women and men are much closer together on the current-self than on the possibleself composites; however, in the other, femininestereotyped domain, the gender difference is about the same for the current- and possible-self composites. A MANOVA using the four composites as dependent variables showed a multivariate effect of gender, $F(4,708)=53.92, p<.0001$, and subsequent univariate analyses showed that women and men differed significantly at the .001 level or lower on all four composites.

For the high school sample, the pattern of results was similar but not identical to the university samples. The three-way interaction was not significant. However, a significant effect of gender $\times$ domain, $F(1,445)=63.15, p<.0001$, described a pattern in which, as in the other samples, girls rated themselves higher on both the current- and possible-self composites within the domain that emphasized the arts and communication, whereas boys rated themselves higher on both composites within the domain that emphasized mathematics and science. Also, a significant effect of gender $\times$ current- vs. possibleself, $F(1,445)=10.90, p<.001$, described a pattern in which there was a larger gap between boys and girls on possible-self than on current-self ratings. A MANOVA using the four composites as dependent variables showed a multivariate effect of gender, $F(4,442)=22.31, p<.0001$, and subsequent univariate analyses showed that girls and boys differed significantly at the .01 level or better on all four composites.

\section{Relationship Between Current- and Possible-Self Ratings}

Table VIII shows the intercorrelations among the higher order composites for the RU-A sample from Study 1 and both samples in Study 2. For both university samples, the current-self MSci composite correlates positively and significantly with the possible-self Power composite, and the current-self ACL composite correlates positively and significantly with the possible-self People composite. As well, there are significant negative relationships between the current-self MSci composite and the possible-self People composite, between the current self ACL composite and the possible-self Power composite, and between the two current-self higher order composites. There is no significant relationship between the two possible-self composites.

For the high school sample, however, there is not such a clear divide between two domains. Like the university samples, this group shows significant positive correlations between the current-self MSci composite and the possible-self Power composite as well as between the current-self ACL composite and the possible-self People composite. However, unlike the university samples, the high school students show no significant negative correlations between the two current-self composites or between MSci and People, and they show significant positive correlations 

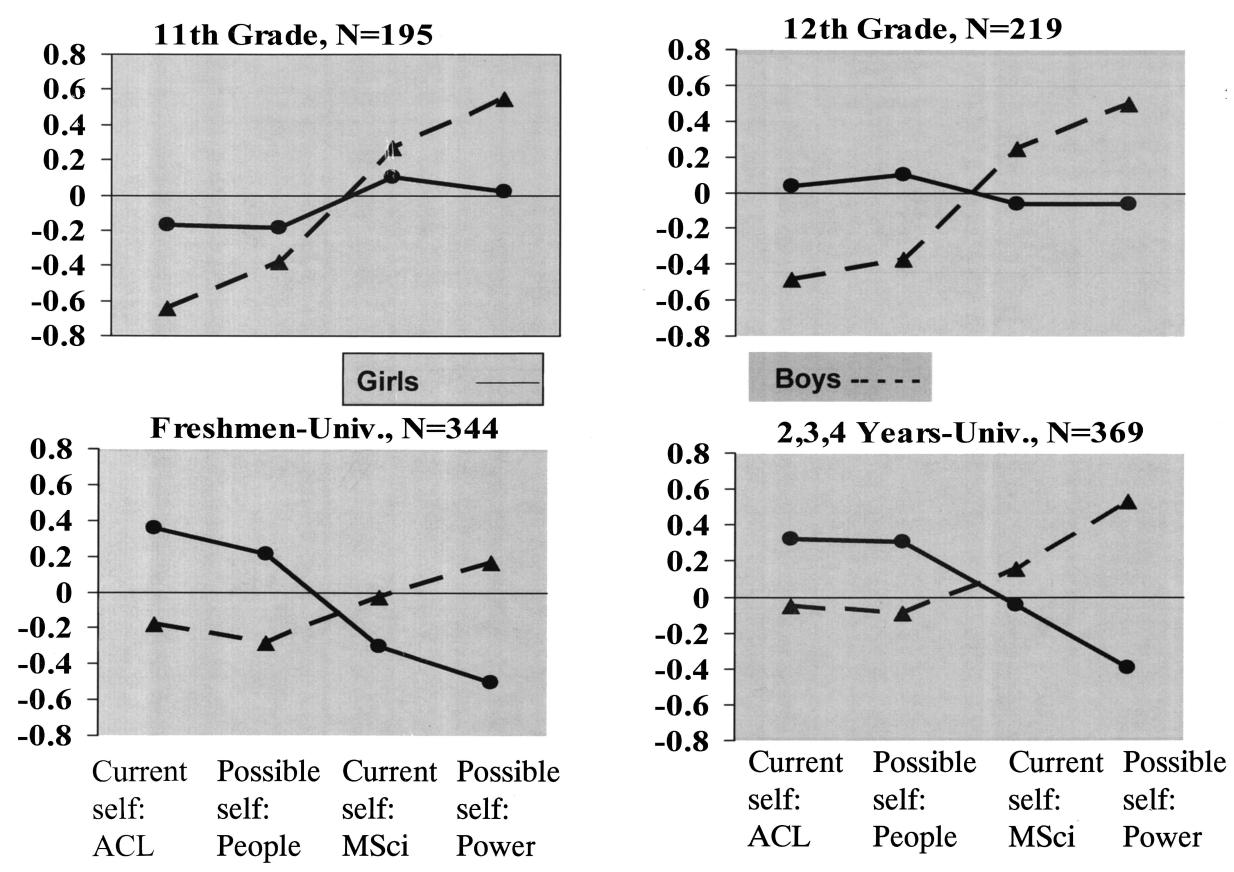

Fig. 2. Mean higher order current- and possible-self composite scores (as $z$ scores) for Study 2 respondents at different educational stages.

between the current-self ACL composite and the possible-self Power composite and between the two possible-self composites.

Associations Among Higher- Order Composites by Year of Education. Because of the differences observed between the high school and university data, it was of interest to examine patterns of gender differences in higher order composite scores by year of education. Figure 2 shows the higher order current- and possible-self composite self scores (as $z$ scores) for respondents at different educational stages: 11th grade, 12th grade, freshman university year, and upper level university years. The difference between high school and university samples appears to be marked by gendered patterns. For both groups, composite scores on the ACL and People domains are higher for university than high school students. However, the scores on the possible-self Power composite appear dramatically lower among university than high school students for women/girls only.

A mixed $4 \times 4$ (educational stage by composite) MANOVA using only female participants revealed a significant interaction between type of self-view composite score and educational stage, $F(3,678)=$ $22.45, p<.0001$. The means are graphed in Fig. 3. A MANOVA in which the four composites were used as dependent variables revealed a significant multivariate effect of educational stage, $F(4,677)=19.84, p<$
.0001. Subsequent univariate tests revealed that the effect of educational stage was significant for all four composites.

Simple contrasts (Norušis, 1985) were run separately for female and male students in order to identify likely differences among educational levels with respect to each of the four higher order composite scores. The absolute values in Table IX represent pairwise differences in standardized means on each of four, higher order composite variables for the groups being compared. These analyses suggested that female university students view themselves and their possibilities as stronger than female high school students do in the feminine-stereotyped domain of arts, literature, humanities, and communication and as less strong than female high school students do in the masculine-stereotyped domain of mathematics, science, technology and arguing. Female university students at both freshmen and upper-class levels differed significantly from female students in both the 11th and 12 th grades on the current-self ACL composite. Differences within high school and university levels were not significant. For the possible-self People composite, students in 12 th grade at both university levels differed significantly from students in the 11th grade. On the current-self Math/Science composite, university freshmen were significantly lower than the other three groups, and no other mean differences were 


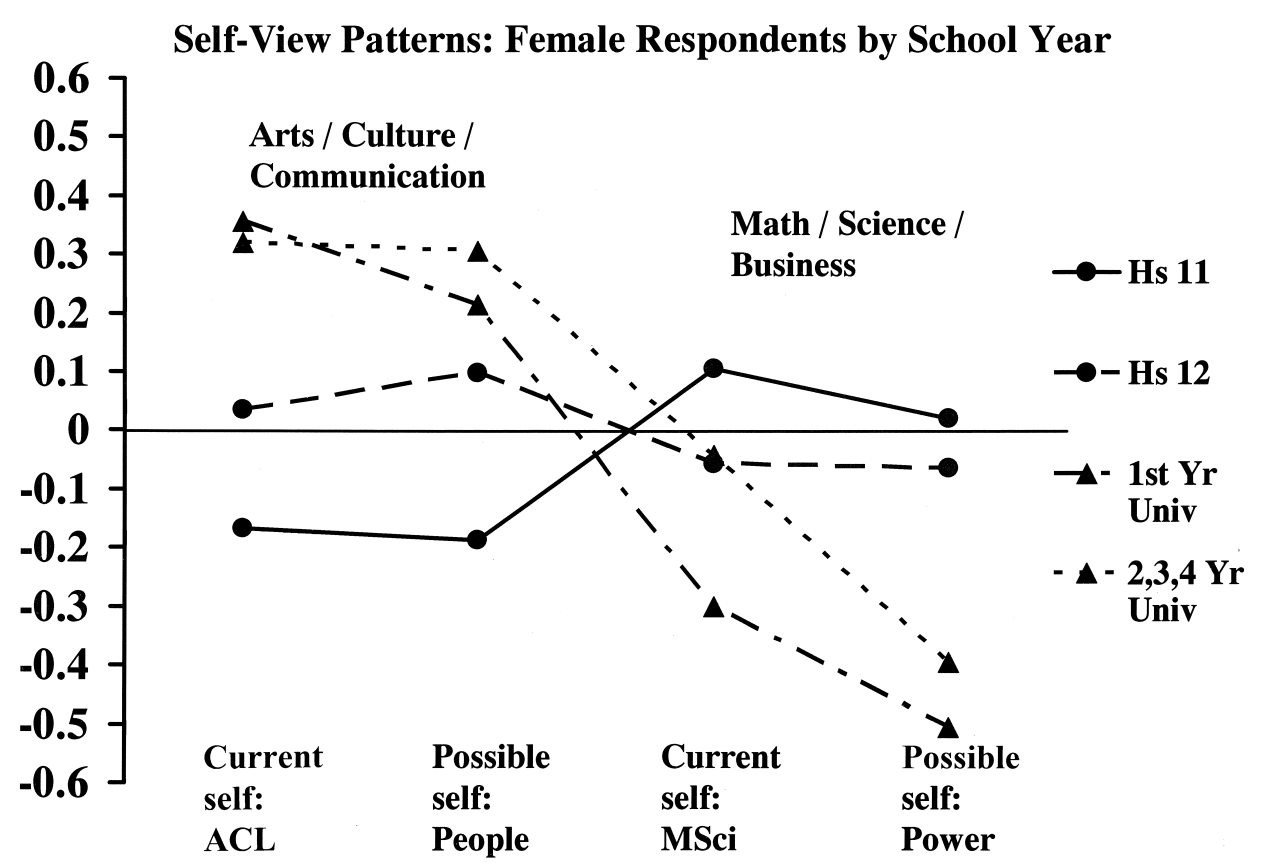

Fig. 3. Mean higher order composite scores (as $z$ scores) for female respondents at different educational stages.

significant. On the possible-self Power composite, university women at both levels differed significantly from both 11th and 12th grade students. Differences within high school and university levels were not significant.

For male students, there were also some differences according to educational stage. Again, a mixed multivariate analysis of variance revealed a signifi- cant interaction between type of self-view composite and educational stage, $F(3,441)=10.06, p<.0001$. The means are graphed in Fig. 4. A MANOVA in which the four composites were used as dependent variables demonstrated a significant multivariate effect of educational stage, $F(4,438)=44.49, p<$ .0001 . Subsequent univariate tests revealed that the effect of educational stage was significant only for the

Table IX. Mean Standardized Difference Scores on Simple, Pair-Wise Comparisons

\begin{tabular}{llccc}
\hline & \multicolumn{3}{c}{ L.A.S.S. higher order composite variables (z scores) } \\
\cline { 2 - 5 } Education level contrasts & $\begin{array}{c}\text { ACL current- } \\
\text { self }\end{array}$ & $\begin{array}{c}\text { People possible- } \\
\text { self }\end{array}$ & $\begin{array}{c}\text { MSci current- } \\
\text { self }\end{array}$ & $\begin{array}{c}\text { Power possible- } \\
\text { self }\end{array}$ \\
\hline Female students & & & & .086 \\
Hs 11th Grade vs. Hs 12th Grade & .203 & $.283^{a}$ & .163 & $.626^{b}$ \\
Hs 11th Grade vs. 1st Yr. Univ. & $.523^{b}$ & $.400^{b}$ & $.408^{b}$ & $.417^{b}$ \\
Hs 11th Grade vs. 2nd-4th Yr. Univ. & $.490^{b}$ & $.492^{b}$ & .149 & $.441^{b}$ \\
Hs 12th Grade vs. 1st Yr. Univ. & $.320^{b}$ & .117 & $.245^{a}$ & $.331^{b}$ \\
Hs 12th Grade vs. 2nd-4th Yr. Univ. & $.287^{b}$ & .209 & .017 & .109 \\
1st Yr. Univ. vs 2nd-4th Yr. Univ. & .034 & .092 & $.259^{b}$ & .045 \\
Male students & & & .022 & $.375^{b}$ \\
Hs 11th Grade vs. Hs 12th Grade & .157 & .009 & $.293^{a}$ & .011 \\
Hs 11th Grade vs. 1st Yr. Univ. & $.467^{b}$ & .092 & .112 & $.330^{a}$ \\
Hs 11th Grade vs. 2nd-4th Yr. Univ. & $.597^{b}$ & $.283^{a}$ & $.271^{a}$ & .034 \\
Hs 12th Grade vs. 1st Yr. Univ. & $.310^{a}$ & .083 & .091 & $.364^{b}$ \\
Hs 12th Grade vs. 2nd-4th Yr. Univ. & $.440^{b}$ & $.274^{a}$ & .181 & .191 \\
1st Yr. Univ. vs 2nd-4th Yr. Univ. & .130 & & & \\
\hline
\end{tabular}

${ }^{a}$ Contrast estimate significant at $p<.05$.

${ }^{b}$ Contrast estimate significant at $p<.01$. 


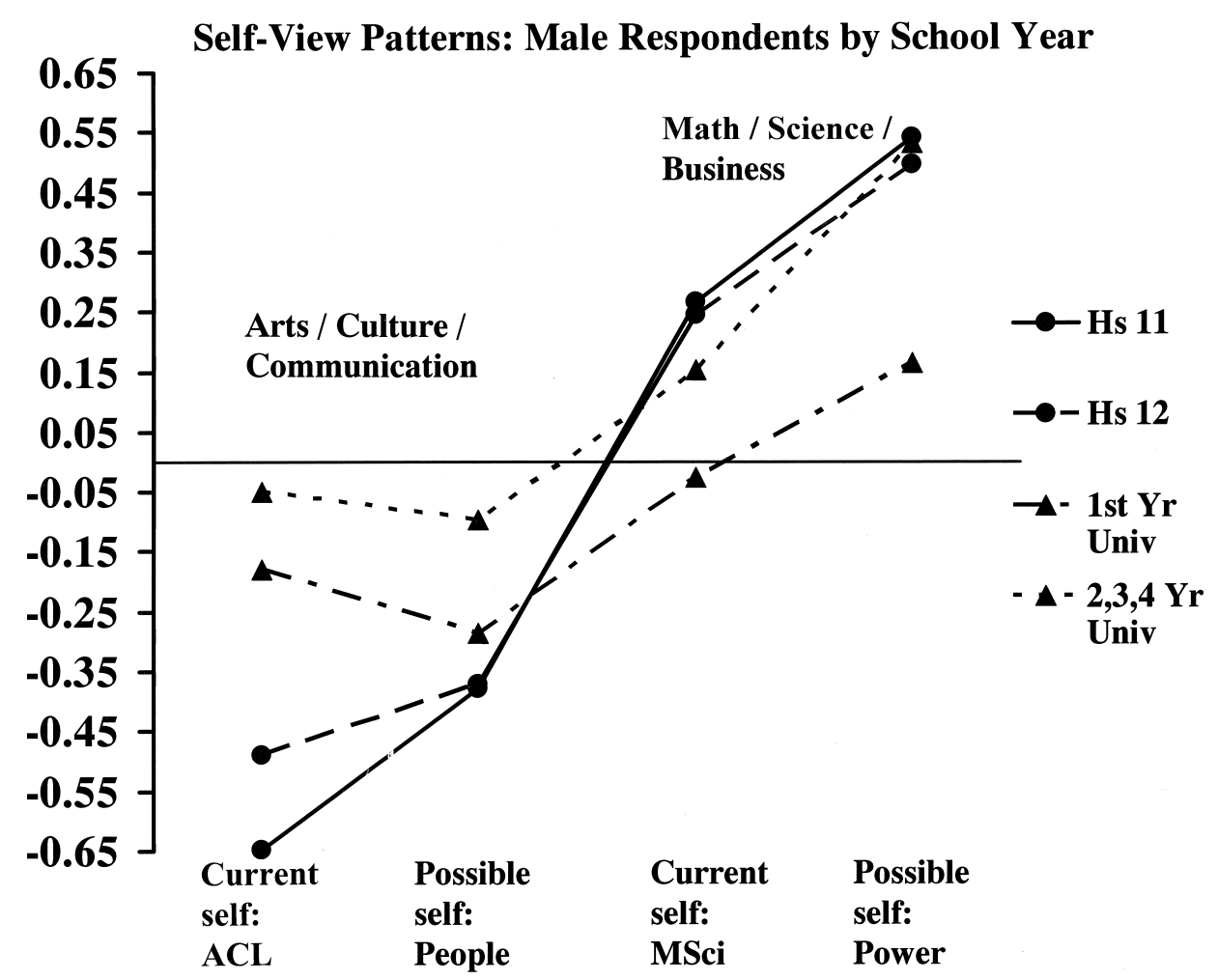

Fig. 4. Mean higher order composite scores (as z scores) for male respondents at different educational stages.

current-self ACL and the possible-self Power composites. As shown in Table IX, simple contrasts suggest that, like female respondents, men at the university level view their academic strengths and possibilities as stronger than do boys at the high school level in the domain of arts, literature, humanities, and communication. Male students at both university levels differed significantly from male students at both high school levels on the current-self ACL composite; differences within high school and university levels were not significant. On the possible-self People composite, male respondents in the upper university years differed significantly from those in the 11th and 12th grade, but not from freshmen. With respect to the domain that includes math, science, technology, and arguing, however, there is no indication of increasingly confident academic self-views with increasing levels of education. Rather, university freshmen exhibited lower means on the current-self Math/Science composite than both groups of high school boys, and their means on the possible-self Power composite are significantly lower than all three other groups. No other group differences on these composite scores were significant.

\section{Discussion}

The patterns apparent in the RU-B sample closely replicate those obtained in the RU-A sample discussed in Study 1, despite differences between the two samples in terms of age and stage of education. The high school data, although similar, revealed a pattern of fewer gender differences in academic self-views.

Although the data are cross-sectional rather than longitudinal, they suggest both some similarities and some intriguing differences related to educational stage. In terms of similarities, the now familiar "divide" pattern appears at all stages: in the arts/communication/culture domain, the female respondents rate themselves as stronger than the male respondents, and this reverses in the math/science/business domain. Also in every group, within the math/science/business domain, the gap between female and male respondents is greater in the realm of possible selves than in the realm of current-self-appraisals.

Although these are not longitudinal data, differences among the patterns in these groups hint at a 
process of change and of increasing divergence between young women and men in their self-views. High school and university women's self-ratings are quite different in at least one respect: university women give lower self-ratings on the Power composite-perhaps closing off for themselves such possibilities as business, engineering, computing, and law. This is especially intriguing because it is the women who go on to college who are in the best position to pursue such powerful careers. For the high school women, currentself-views and possible-self-views seem to be in line with each other. For university women this is also true within the arts/communication/culture domain, but within the math/science/business domain there is a larger discrepancy. Furthermore, these university women apparently see future pursuit of the academic areas encompassed in the Power composite as far less possible for themselves than the young women in high school do.

Differences correlated with educational stage also appear for male respondents. The young men in high school give current-self ratings on the ACL composite that are considerably lower than do the men in the university samples. This may represent a change in self-views experienced by young men as they make this transition or it may be a function of sample selection. One thing that seems clear, however, is that the young men, at all levels, are strongly open to the possibilities of pursuing the academic directions included in the Power composite-and their willingness to consider these possibilities outstrips their currentself ratings in these areas.

\section{GENERAL DISCUSSION}

These data lead to concern about a pattern of gaps between women and men seen in many samples. The literature on career development suggests strongly that self-views have a large impact on vocational decisions. Bandura's self-efficacy theory (Bandura, 1977, 1977), which is broadly supported by research, postulates that a person's beliefs regarding competence in specific domains influences choice, performance, and persistence in endeavors that require these competencies. Research shows that occupational attainment in adulthood is predicted by job aspirations and belief in one's own abilities in adolescence (Schoon, 2001).

Clearly, in these samples, the rating patterns of students' perceptions of their current academic selves are linked to their visions of what is possi- ble for them in the future. Also, very clearly, there is a strong divide, particularly among university students, between two academic "futures"- one that emphasizes science, numbers, reasoning, and argument, and another that emphasizes culture, people, and selfexpression-such that perceiving oneself as oriented toward one group is strongly and reliably negatively associated with perceiving oneself as oriented toward the other. This "divided future" appears to parallel gender stereotypes. The data are very consistent in revealing a "divide" between young women and men in the academic realms in which they rate themselves as strong. These students are still absorbing a message that certain academic domains are more appropriate for one gender or the other.

One especially troubling thing these data show is that, in some cases, there is a large gap between students' current-self evaluations and their perceptions of what is possible for them in the future. Over and over again, the data show that, for women, currentself-views in terms of mathematics and science may be more comparable to those of their male counterparts than are their possible- self-views of future study in the areas implicated by these competencies. It appears that, even though women and men in these samples differ somewhat in how they see their current academic selves, these self-views translate into an even more different set of possibilities envisioned by these young women and men.

Dynamic, longitudinal data will be necessary to investigate the suggestion raised by these data that young women may be actively closing off possibilities for themselves as they move from high school to college. However, whether or not these findings represent such a process, they do show that one area of useful intervention for young women's academic selfviews lies in the realm of possible selves. Research has shown that role models can inspire and guide students' academic aspirations (Hackett, 1985; Lockwood \& Kunda, 1997), and even in the time-limited environment of the laboratory, the presence of competent female role models has a protective effect on young women's mathematics performance (Marx \& Roman, 2002). Interviews with women employed in the areas of mathematics, science, and technology indicate that verbal persuasions (e.g., from mentors) and vicarious experiences (e.g., from role models) were critical sources of these women's sense of self-efficacy (Zeldin $\&$ Pajares, 2000). More research is needed on precisely how role models affect students' possible selves.

It is worth noting, in closing, the increasing awareness that the workforce is more fluid and job 
tenure less predictable and certain than even two decades ago. As Fitzgerald and Harmon (2001) have written, "career planning is now a lifetime task rather than simply a matter of a good initial choice" (p. 226). A broad range of possible selves would be helpful in such an occupational environment, and it is a poor idea to restrict that range according to gender. Neither women nor men can afford, in such an environment, to buy into the "divide" that appears in these data.

\section{ACKNOWLEDGMENTS}

This research was funded in part by a grant from the Saint Albans Foundation. I am grateful to the many instructors and students who cooperated with this study. I thank Wayne K. Andrew for his assistance with data analysis, and Ginger Hudson, Lori Wilson, Sandra Morse, Ellen Wrisley, Melanie Rogers, Nicole Childers-Daniels, Nate Fancher, Michelle Rice, Greg Kerwin, Maggie Haynes, Titus Lane, Carly Saunders, and Dolores Paxton for help with data collection.

\section{REFERENCES}

Adamuti-Trache, M., \& Andres, L. (2002). Issues of retention of B.C. young women through the science and engineering pipeline. In Women in a knowledge-based society: Proceedings of the 12th International Congress on Women in Engineering and Science, Paper \#245. CD-ROM available from the International Network of Women in Engineering and Science, at http://www.inwes.org/

Bandura, A. (1977). Self-efficacy: Toward a unifying theory of behavioral change. Psychological Review, 84, 191-215.

Bandura, A. (1997). Self-efficacy: The exercise of control. New York: Freeman.

Brown, J. D. (1998). The self. Boston: McGraw-Hill.

Cross, S. E. (2001). Training the scientists and engineers of tomorrow: A person-situation approach. Journal of Applied Social Psychology, 31, 296-323.

Cross, S. E., \& Vick, N. V. (2001). The interdependent self-construal and social support: The case of persistence in engineering. Personality and Social Psychology Bulletin, 27, 820-832.

Eagly, A. H. (1987). Sex differences in social behavior: A social-role interpretation. Hillsdale, NJ: Erlbaum.

Eccles, J. (1987). Gender roles and women's achievement-related decisions. Psychology of Women Quarterly, 11, 135-172.

Fitzgerald, L. F., \& Harmon, L. W. (2001). Women's career development: A postmodern update. In F. T. L. Leong \& A. Barak (Eds.). Contemporary models in vocational psychology (pp. 207-230). Mahwah, NJ: Erlbaum.

Gaudet, J., \& Lapointe, C. (2002). Girls and science: An untimely missed rendezvous. In Women in a knowledge-based society: Proceedings of the 12th International Congress on Women in Engineering and Science, Paper \#41. CD-ROM available from the International Network of Women in Engineering and Science, at http://www.inwes.org/

Hackett, G. (1985). Role of mathematics self-efficacy in the choice of math-related majors of college women and men: A path analysis. Journal of Counseling Psychology, 32, 47-56.

Hartman, H., \& Hartman, M. (2002). Comparing female and male experiences in the Rowan undergraduate engineering program. In Women in a knowledge-based society: Proceedings of the 12th International Congress on Women in Engineering and Science, Paper \#220. CD-ROM available from the International Network of Women in Engineering and Science, at http://www.inwes.org/

Ivie, R., \& Stowe, K. (2002). U.S. women in academic physics. In Women in a knowledge-based society: Proceedings of the 12th International Congress on Women in Engineering and Science, Paper \#169. CD-ROM available from the International Network of Women in Engineering and Science, at http://www.inwes.org/

Lips, H. M. (1993). Bifurcation of a common path: Gender splitting on the road to engineering and physical science careers. Initiatives, 55(3), 13-22.

Lips, H. M. (1995). Through the lens of mathematical/scientific selfschemas: Images of students' current and possible selves. Journal of Applied Social Psychology, 25, 1671-1699.

Lips, H. M. (1996, August). Linking students' current and possible selves to teaching and learning in academic domains. Paper presented at the XXVI International Congress of Psychology, Montreal, Canada.

Lips, H. M. (1998, June). Gendered possibilities: Young women's and men's visions of their future power and competence. Invited plenary address, Canadian Psychological Association convention, Edmonton, Canada.

Lips, H. M., \& Casey, J. F., III (1996, March). Fuzzy effects in scales assessing self-schemas and possible selves. Paper presented at the annual convention of the Southeastern Psychological Association, Norfolk, VA.

Lips, H. M., \& Wilson, L. A. (1997, October). What is possible for me? Gender and academic self-concept among university students. Paper presented at the annual conference of the Southern Regional Chapter of the Association for Women in Psychology, Wilmington, NC.

Lockwood, P., \& Kunda, Z. (1997). Superstars and me: Predicting the impact of role models on the self. Journal of Personality and Social Psychology, 73, 91-103.

Mahoney, M. J., \& Lyddon, W. J. (1988). Recent developments in cognitive approaches to counseling and psychotherapy. Counseling Psychologist, 16, 190-234.

Markus, H., \& Nurius, P. (1986). Possible selves. American Psychologist, 41, 954-969.

Marx, D. M., \& Roman, J. S. (2002). Female role models: Protecting women's math test performance. Personality and Social Psychology Bulletin, 28, 1183-1193.

Nosek, B. A., Banaji, M. R., \& Greenwald, A. G. (2002). Math = male, $\mathrm{me}=$ female, therefore math [not equal to] me. Journal of Personality and Social Psychology, 83, 44-59.

Norušis, M. J. (1985). SPSS ${ }^{X}$ Advanced Statistics Guide. New York: McGraw-Hill.

Ornstein, N. J., Mann, T. E., Malbin, M. J., \& Bibby, R. E. (1993). Vital statistics of Congress, 1993. Washington, DC: American Institute for Policy Research.

Räty, H., Vänskä, J., Kasanen, K., \& Kärkkäinen, R. (2002). Parents' explanations of their child's performance in mathematics and reading: A replication. Sex Roles, 46, 121-128.

Ross, L., \& Nisbett, R. E. (1991). The person and the situation: Perspectives of social psychology. New York: McGraw-Hill.

Schoon, I. (2001). Teenage job aspirations and career attainment in adulthood: A 17-year follow-up study of teenagers who aspired to become scientists, health professionals, or engineers. International Journal of Behavioral Development, 25, 124-132.

Steele, J., James, J. B., \& Barnett, R. C. (2002). Learning in a man's world: Examining the perceptions of undergraduate women in male-dominated academic areas. Psychology of Women Quarterly, 26, 46-50.

The corporate elite: Portrait of a CEO. (1993, October 11). Business Week, 64-70, 82-101.

Zeldin, A. L., \& Pajares, F. (2000). Against the odds: Self-efficacy beliefs of women in mathematical, scientific, and technological careers. American Educational Research Journal, 37, 215-246. 